\title{
Failure Analysis of Clamp Crack on TA Equipment in Converter Station
}

\author{
Jun Wang ${ }^{1, *}$, Junling Tan ${ }^{2}$, Jun Liu ${ }^{3}$, Jie Gong ${ }^{4}$, Jiarui Hu${ }^{1}$, Yi Xie ${ }^{1}$, Junjun Chen ${ }^{1}$ and Weike Liu ${ }^{1}$ \\ ${ }^{1}$ State Grid Hunan Electric Power Company Limited Research Institute, Changsha 410007, China \\ ${ }^{2}$ Hunan Xiangdian Boiler Pressure Inspection Center Co., Ltd, Changsha 410007, China \\ ${ }^{3}$ State Grid Hunan Electric Power Company Limited Yueyang Power Supply Company, Changsha 414100, China \\ ${ }^{4}$ State Grid Hunan Electric Power Company Limited Maintenance Company Changsha 410004, China
}

\begin{abstract}
Through macro inspection, chemical composition analysis, hardness test, tensile performance test, microstructure inspection and scanning electron microscope analysis, the causes of clamp crack on TA equipment in the $500 \mathrm{kV}$ AC filter field of the $\pm 800 \mathrm{kV}$ converter station were analyzed. The results show that improper selection of the manufacturing process of the equipment clamps will cause more micro-defects inside it, leading to poor mechanical properties and excessive internal stress, which are the main causes of cracking. Corresponding measures are put forward to improve the manufacturing quality of equipment clamps, which can avoid similar failures from happening again.
\end{abstract}

\section{Introduction}

Equipment clamps are important fittings widely used in power grid systems. They are used to connect the down conductors of busbars to the outgoing terminals of electrical equipment and to connect electrical equipment. It consists of a fastening wire part and an electrical equipment connection part. The former is a tubular structure and the latter is a terminal board (wiring board) structure $^{[1-4]}$. Aluminum equipment clamps are usually processed by aluminum tube welding terminal plates or integral casting methods. The joint between the tubular structure and the terminal board is a weak part, which is prone to failure during use and endangers the safe and stable operation of the power grid $^{[5-7]}$.

In this paper, a failure of a clamp crack on TA equipment in the $500 \mathrm{kV} \mathrm{AC}$ filter field of the $\pm 800 \mathrm{kV}$ converter stationa was studied. Through macro inspection, chemical composition analysis, hardness test, tensile performance test, microstructure inspection and scanning electron microscope analysis, the causes of clamp crack were analyzed to provide a reference for equipment clamp manufacturing, inspection and acceptance.

\section{Experiment section}

A FOUNDRY-MASTER PRO Oxford full-spectrum direct-reading spectrometer was used to analyze the chemical composition of the cracking equipment clamp. Three $60 \mathrm{~mm} \times 20 \mathrm{~mm} \times 8 \mathrm{~mm}$ samples were cut from the wiring board, and the hardness was tested on the HBE-3000A electronic Brinell hardness tester. The detection position is shown in Fig.1. Cut 3 rectangular tensile samples with a cross-section size of $20 \mathrm{~mm} \times$ $8 \mathrm{~mm}$ from the terminal board, and perform a room temperature tensile test on a UTM5105 universal testing machine. Observe the microstructure of the crack clamp under the Zeiss Axio Observer A1m metallographic microscope. The metallographic samples were further observed and analyzed by ZEISS EVO18 scanning electron microscope (SEM).

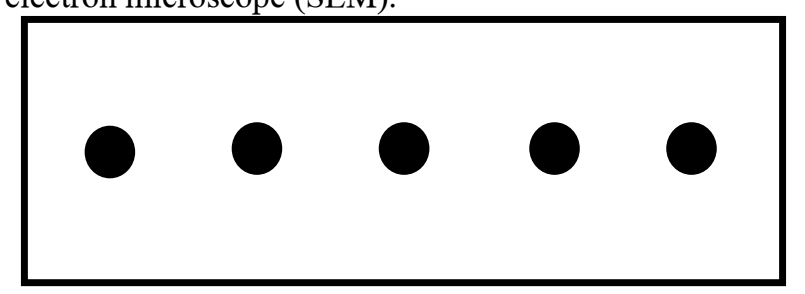

Fig. 1. Schematic diagram of hardness testing position

\section{Results and discussion}

\subsection{Macro inspection}

Penetration testing is performed on the cracking equipment clamps, and the crack locations are located on both sides of the wiring board, as shown in Fig.2. Further inspection found that cracks on both sides penetrated the side of the terminal board, as displayed in Fig.3.

\footnotetext{
* Corresponding author: 279091498@qq.com
} 


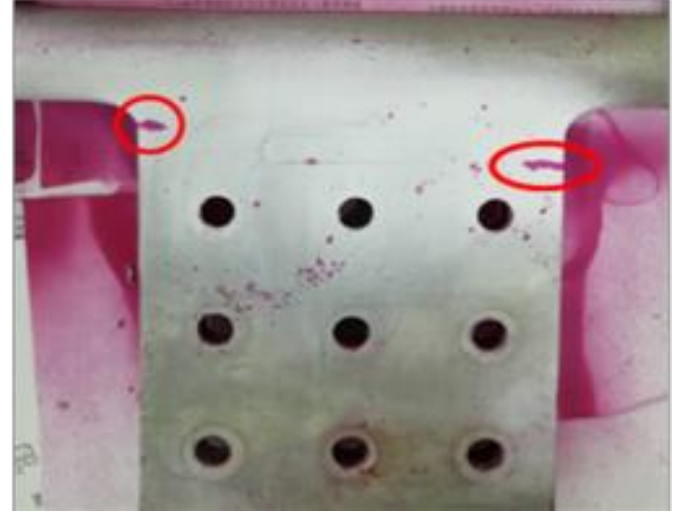

Fig. 2. Cracking location of equipment clamp
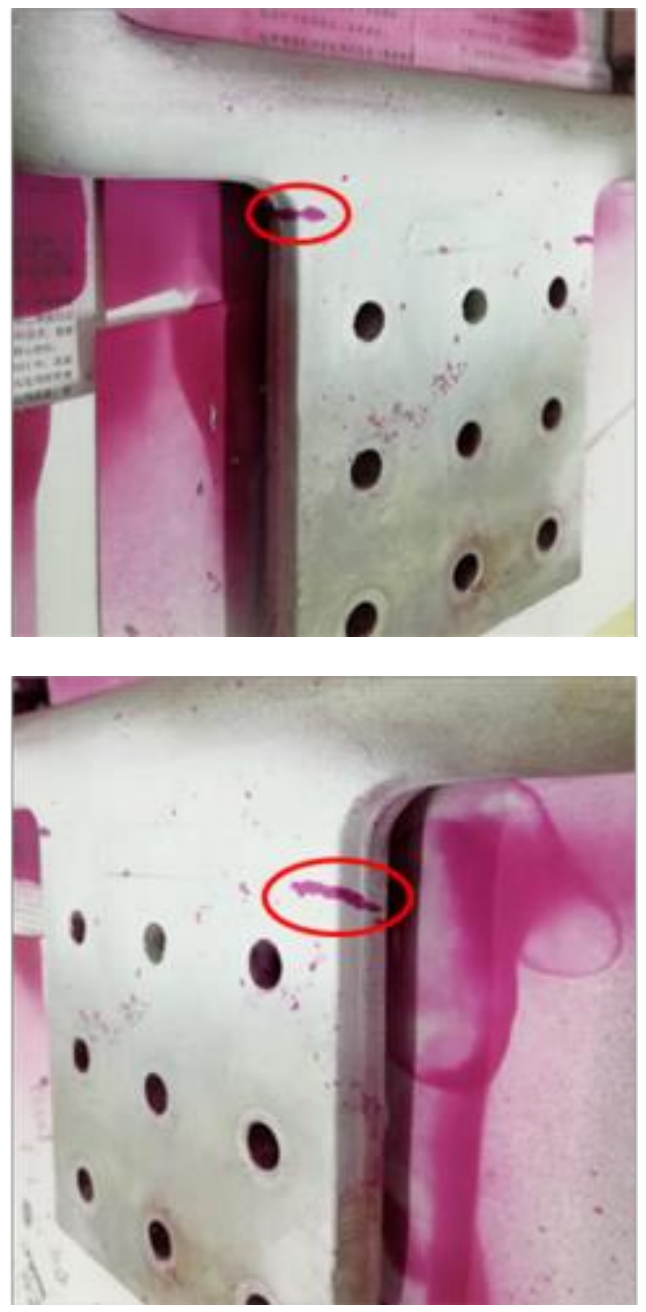

Fig. 3. Crack penetrates to the side

\subsection{Chemical composition testing}

The chemical composition of wiring tube part and wiring board part of equipment clamp were illustrated in Table 1 and Table 2 respectively. The average chemical composition of both parts meets the requirements of 1050A (L3) in GB / T 3190-2008 "Chemical Composition of Wrought Aluminum and Aluminum Alloys". It can be seen that the entire equipment clamp is cast from L3 industrial pure aluminum.
Table 1. Chemical composition of wiring tube part.

\begin{tabular}{|c|c|c|c|}
\hline $\begin{array}{c}\text { Element } \\
\text { content/\% }\end{array}$ & Al & Si & Fe \\
\hline Test point 1 & 99.58 & 0.19 & 0.25 \\
\hline Test point 2 & 99.64 & 0.18 & 0.21 \\
\hline $\begin{array}{c}\text { Test point 3 } \\
\text { average } \\
\text { value }\end{array}$ & 99.61 & 0.14 & 0.20 \\
\hline $\begin{array}{c}\text { standard for } \\
\text { L3 }\end{array}$ & $\geqslant 99.5$ & $\leqslant 0.25$ & $\leqslant 0.40$ \\
\hline
\end{tabular}

Table 2. Chemical composition of wiring board part.

\begin{tabular}{|c|c|c|c|}
\hline $\begin{array}{c}\text { Element } \\
\text { content } \%\end{array}$ & $\mathrm{Al}$ & $\mathrm{Si}$ & $\mathrm{Fe}$ \\
\hline Test point 1 & 99.67 & 0.21 & 0.18 \\
\hline Test point 2 & 99.63 & 0.23 & 0.11 \\
\hline $\begin{array}{c}\text { Test point 3 } \\
\text { average } \\
\text { value }\end{array}$ & 99.62 & 0.22 & 0.13 \\
\hline $\begin{array}{c}\text { standard for } \\
\text { L3 }\end{array}$ & $\geqslant 99.64$ & 0.22 & 0.14 \\
\hline
\end{tabular}

\subsection{Hardness measurement}

The Brinell hardness of wiring board part of equipment clamp was measured, and the result was shown in Table 3. It can be seen that the Brinell hardness of the wiring board meets the requirements of $1050 \mathrm{~A}$ (L3) in GB / T 3190-2008 "Chemical Composition of Deformed Aluminum and Aluminum Alloys".

Table 3. Brinell hardness of wiring board part (HB)

\begin{tabular}{|c|c|c|}
\hline Test number & Brinell hardness & $\begin{array}{c}\text { Standard } \\
\text { requirement }\end{array}$ \\
\hline 1 & 32 & \multirow{2}{*}{$30 \sim 45$} \\
\hline 2 & 33 & \\
\hline 3 & 31 & \\
\hline average value & 32 & \\
\hline
\end{tabular}




\subsection{Tensile performance test}

Three tensile samples were cut from the wiring board part of equipment clamp for tensile tests. The results are shown in Table 4. The tensile strength of the wiring board does not meet the requirements of DL / T 346-2010 "Equipment Clamp" for tensile strength not lower than 78Mpa.

Table 4. Tensile test results

\begin{tabular}{|c|c|c|}
\hline Sample number & $\begin{array}{c}\text { Section size } \\
(\mathrm{mm} \times \mathrm{mm})\end{array}$ & $\begin{array}{c}\text { tensile strength } \\
(\mathrm{MPa})\end{array}$ \\
\hline 1 & $19.98 \times 8.01$ & 72 \\
\hline 2 & $20.02 \times 7.98$ & 69 \\
\hline 3 & $20.01 \times 7.97$ & 73 \\
\hline $\begin{array}{c}\text { Standard } \\
\text { requirement }\end{array}$ & $/$ & $\geqslant 78$ \\
\hline
\end{tabular}

\subsection{Micro analysis}

Take samples from the wiring board part of equipment clamp, and perform metallographic test after grinding, polishing and etching. The metallographic structures of the area near the crack and far from the crack are shown in Fig. 4 and 5, respectively. It can be seen that there are a lot of micro-cracks in the structure in both area, which indicates that the casting process of the equipment clamp is poor ${ }^{[8]}$.
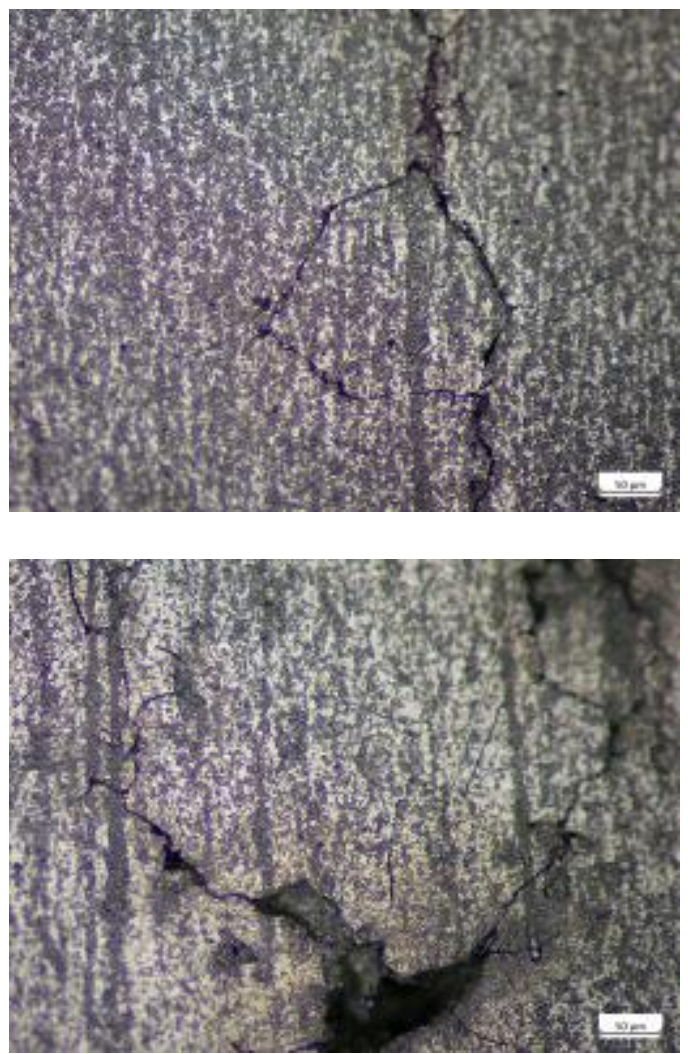

Fig. 4. Metallographic structure near the crack
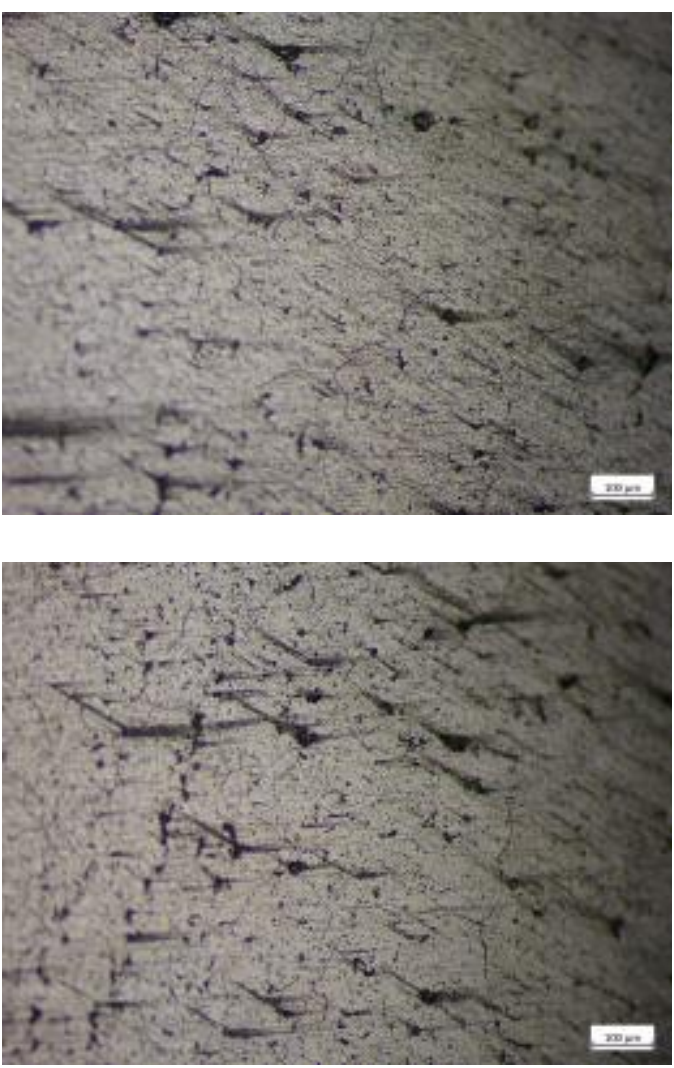

Fig. 5. Metallographic structure away from the crack

\subsection{Scanning electron microscope analysis}

Samples were taken from the area near the cracks of the equipment clamps, and after grinding and polishing, further scanning electron microscope analysis was performed. The secondary electron image is shown in Fig.6. It can be clearly seen that there are obvious contrast differences in the tissues near the cracks, which shows that there may be segregation in the tissues ${ }^{[9]}$, and the tissues is extremely uneven. The enlarged structure is shown in Fig.7. It can be seen that the microstructure has more micro holes and the structure is relatively loose and not dense.

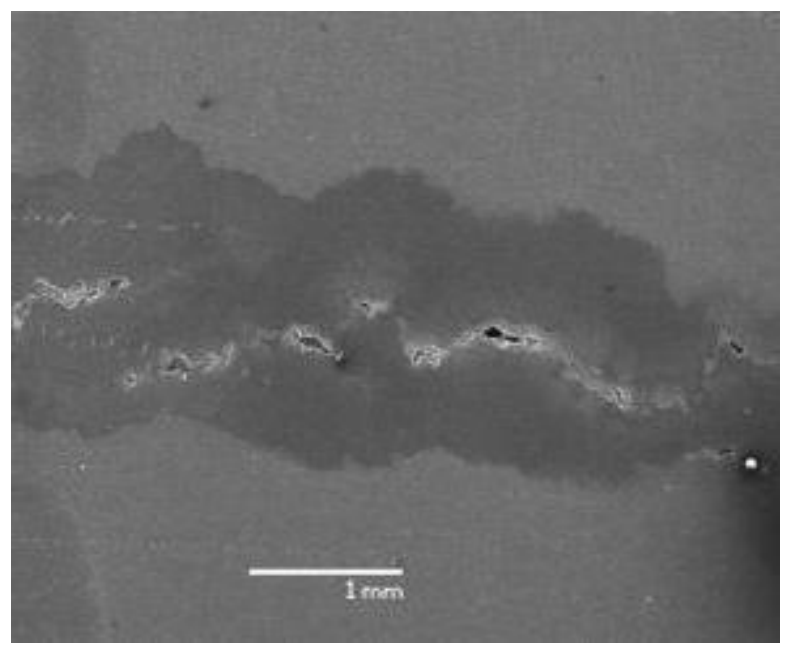

Fig. 6. Secondary electron image near crack 


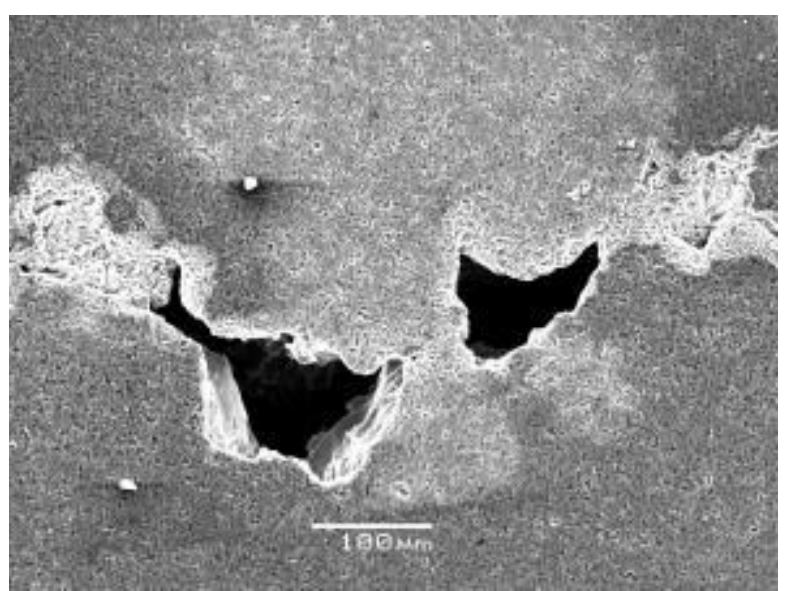

Fig. 7. Enlarged tissue
2. J.J.Liu, S.Gao, J.G.Zhang, Electric Power Construction 35, 3(2014).

3. X.L.Tang, G.H.Chen, J.J.Liu, J.Q.Wang, W.M.Tang, Electric Power Construction 35, 4(2014).

4. Z.S.Wu,S.X.Li, M.Z.Zhang, L.Peng, Hunan Electric Power 39,3 (2019).

5. X.X.Xu, Y.J.Ou,J.T.Feng, Hot Working Technology 40,13(2011)

6. X.Xu, G.Z.Wu,Y.R.Bao, Hot Working Technology 41,7(2012)

7. Y.Xie, J.J.Chen,S.Z.Mu, Casting Technology 34, 3(2012).

8. Y.J.Li, F.S.He, D.X.Sun, W.S.Li, Heavy Casting and Forging 6,11(2016)

9. Z.D.Liu, X.J.Yue, Heavy Casting and Forging $6,7(2011)$

\subsection{Cause analysis}

As can be seen from the foregoing analysis, the equipment clamp is made of L3 industrial pure aluminum, which is formed by the casting process. The casting performance of pure aluminum is not good. Directly using pure aluminum casting production equipment clamps, it is prone to bring in various microstructure defects and reduce its mechanical properties. It is proved by the foregoing test that the hardness meets the standard requirements and the tensile strength does not meet the standard requirements. On the other hand, the casting structure is affected by many process quality control points such as the length of the pouring time, the speed, whether it is stable, whether it is interrupted, etc. It is also prone to be the problems of uneven structure and excessive internal stress. If heat treatment is not performed after casting, it is easy to crack during use.

\section{Conclusion}

1) The equipment clamp is produced by pure aluminum casting molding process, which is prone to various microstructure defects and large internal stress. During use, cracks occur under the influence of external and internal forces.

2) It is recommended to conduct a comprehensive inspection of the same type of equipment clamps of the same manufacturer, and replace them in time if cracks are found.

3) The newly replaced equipment clamps are recommended to be manufactured by the process of aluminum tube pressing and welding with aluminum plates, and the welding quality should be checked to ensure that the equipment clamp quality is acceptable.

\section{References}

1. Z.Z.Lu, W.S.Li, F.S.He, Guangdong Electric Power 28,3 (2015). 